
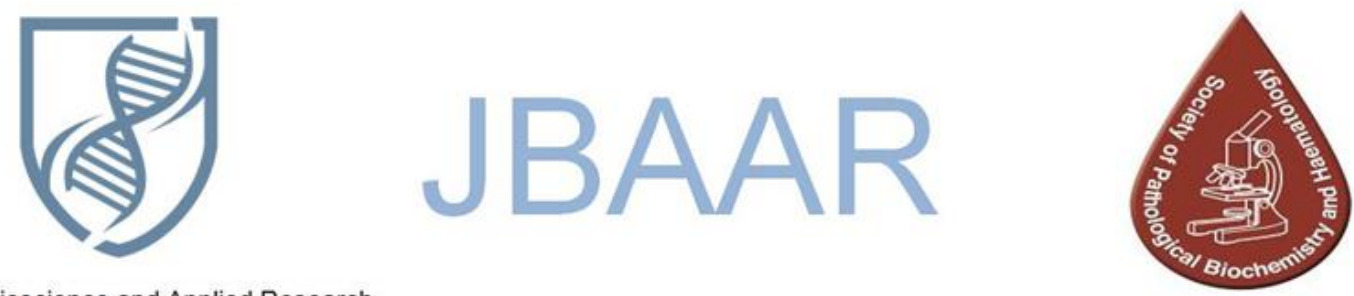

\title{
Protective effect of Zamzam water against kidneys damage induced in male rats: Immunehistochemistry evidence
}

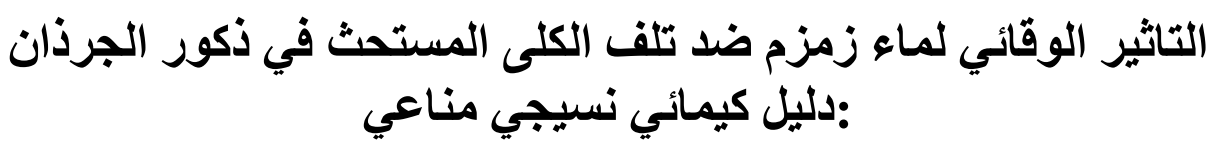

\author{
Abbas,Ch. Mraisel / M.Sc. Pathology / Basic Medical Science Department / Nursing College / \\ Missan University, Iraq . \\ Anas ,S.Abu ali / M.Sc. Physiology / Biology Department /Basic Education College/ Missan \\ University, Iraq . \\ Inas,I.Waheeb/Bch.Biology /Ministryof education /Al-Anbar,Iraq
}

\begin{abstract}
Aim of study: The study was performed to investigate the role of Zamzam water (ZW) as antioxidant against histological changes that occurring in renal damage induced by $n$-hexane intoxication in rats by using immunohistochemical technique.

Method: The experiment was carried out at Environmental Toxicology Laboratory, Department of Environmental Studies, Institute of Graduate Studies and Research, Alexandria University, Alexandria, Egypt. A total of 20 male albino rats weighing 150-170g were obtained from the animal house of the Faculty of Medicine, Alexandria University. The rats were divided to four groups ( 5 rats in each cage). Control group were fed basal diet and given tap water $(100 \mathrm{ml} / \mathrm{cage})$ daily for ten days. In group two the rats were given (n-hexan $300 \mathrm{uL} / \mathrm{kg}$.B.W) mixed with $(0.5 \mathrm{ml})$ corn oil to each rat for last five days of experimental. Group three the rats were given $(100 \mathrm{ml} / \mathrm{cage})$ of Zamzam water as drinking water daily for ten days. Group four the rats were given $(100 \mathrm{ml} / \mathrm{cage})$ of Zamzam water for five days , after that given $\mathrm{n}$-hexan $300 \mathrm{uL} / \mathrm{kg}$.B.W) mixed with $(0.5 \mathrm{ml})$ corn oil last five days of experimental with continuous given Zamzam water. Kidney tissues of each rat were immediately removed and after weighted put into $10 \%$ neutral buffer formalin as a fixative solution. Ki-67 or P53 receptor subunits were examined in deparaffinized sections $(5 \mu \mathrm{m})$ using an Avidin-Biotin-Peroxidase (ABC) immunohistochemical method.

The results: The results observed significantly increase in the weight of the kidneys in the group treated with n-hexane in compared with control group, also relative decrease in weight of the kidneys in the group co-treatment with zamzam water and n-hexane. The detection and distribution of PCNA immunoreactivity (PCNA-ir) in the kidney sections in the different groups under study were observed. Faint positive reaction for PCNA-ir in the kidney sections in control and Zamzam water group, Strong positive reactions for PCNA-ir were detected in n-Hexane group, while a moderate positive reaction for PCNA-ir in the kidney sections with pre -treatment Zamzam water revealed normal structure of malpighian capsule and renal tubules with moderate degeneration of epithelia cell. Conclusions: Exposure to n- hexane showed higher toxic effect with severe kidney damage and treatment with zamzam water alone improved the antioxidant status of rats and could be useful as antioxidant against environmental stress induced by toxic chemicals.
\end{abstract}

Key words: Zamzam water, n- hexane, PCAN-ir, Immunohistochemistry. 


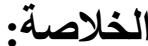

هدف الدراسة :اجريت هذه الدراسة للتحري عن دور ماء زمزم كمضاد للاكسدة ضد التغيرات النسجية الحاصلة في نتيجة لتلف الكلية في ذكور الجرذان

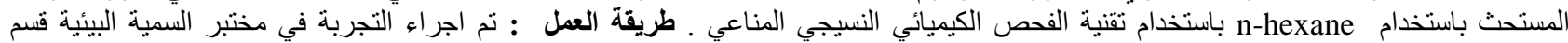

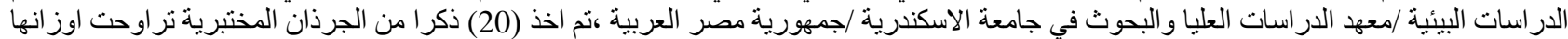

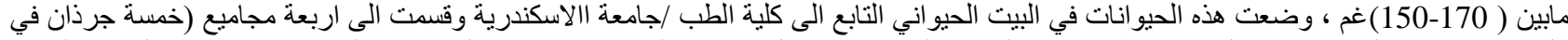

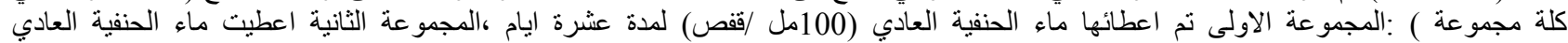

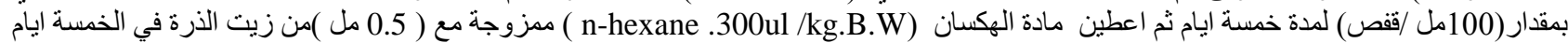

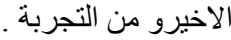

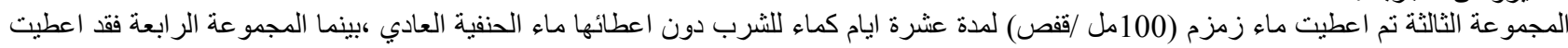

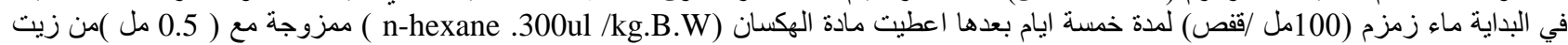

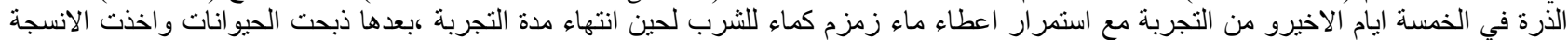

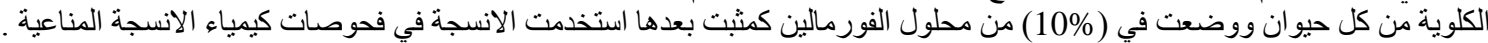

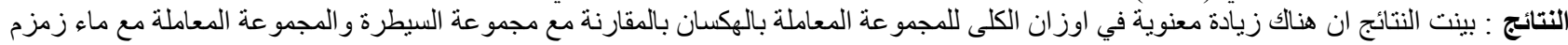

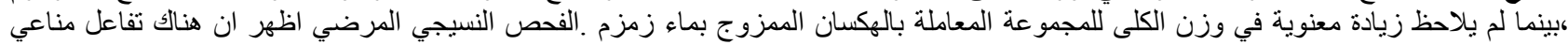

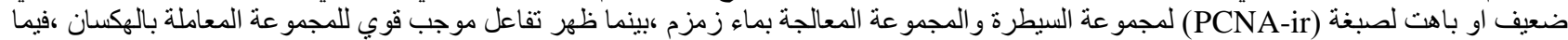

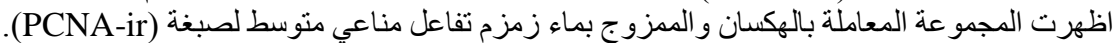

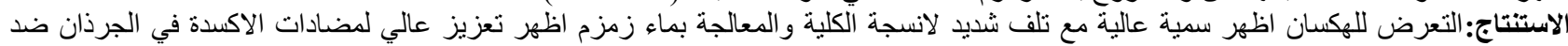
الاجهادات البيئية المستحثة بالسموم الكيماوية الطية

\section{INTRODUCTIN}

Zamzam water (ZW) is naturally hard carbonated type of water with unique physical and chemical properties that are different from any other water. The micromolecules nature of this water it's continuous flow from Zamzam well since 2000BC Interestingly,the source of the water was mentioned in various religious book including the Quran, the Bible and the Torah ( 1).

Millions of people drink (ZW) as cure for many illnesses or for their religious belief . the chemical analysis showed that (ZW) contain 34 different elements. The concentrations of sodium (Na),calcium $(\mathrm{Ca})$,chloride $(\mathrm{Cl})$ and magnesium $(\mathrm{Mg})$ are a higher than the natural water. Few traces of chromium (Cr) ,manganese (Mn)and titanium (Ti) are present in Zamzam water(2,3). The main difference between
$\mathrm{ZW}$ and other water was in the quantity of calcium and magnesium salts, the content of these was slightly higher in $\mathrm{ZW}$, but more significantly, the water contains fluorides that have an effective germicidal action (4). Saif et al (5) were referred that the Zamzam water is ionized water (negative water ) because it have negative charge and show strengthen to antioxidant capacity of animal bodies and reduce oxidative stress in the patients with chronic renal disease ,also has been shown to improve the glycemic control in diabetic rats by unknown mechanisms .

The ZW has a higher PH value (7.9- 8) than the $\mathrm{PH}$ the $\mathrm{PH}$ value for ordinary water $(6.5$ - 7) and neumerous studies have been focused on the relation of $\mathrm{PH}$ and cancer and proved that the cancer cells thrive when they were exposed to low PH medium but can`t survive in alkaline medium (5). 
Tsai et al (6) have been shown protective effect for ZW against hepatotoxicity against carbon tetrachloride which can cause liver damage. Saif et al (5) add that the mechanism of hepato protection of ZW due to its antioxidant effect and ZW can cause increase in hepatic SOD activity with reduce reactive free radicals which reduced oxidative damage to the liver. $\mathrm{ZW}$ also contain iodide, sulphate and nitrate are present in large concentration, therefore large quantity of iodide necessary for thyroid organ of the body and can treat thyroid abnormalities (7).

The alkane n- hexane ,6-carbon aliphatic hydrocarbon $(\mathrm{CnH} 2 \mathrm{n}+2)$ is common component in lacquers, glues and glue thinner is widely used in numerous industrial processes, it colorless volatile organic solvent at room temperature, made from crude oil that is mixed with solvents (8).

Most of n- hexane used in industry is mixed with similar chemicals called solvents and the major use for solvents containing nhexane is to extract vegetable oils from crops such as soybeans, also used as cleaning agents in the printing, textile, furniture and shoemaking industries (9). Nhexane evaporates very easily into the air where it is broken down in a few days ,and most $\mathrm{n}$ - hexane spilled in water floats on the surface where it evaporates into the air .
If $n$ - hexane is spilled on the ground, most of it evaporates before it can soak in to soil, also noticed $n$ - hexane not concentrated by plants, fish, or animals (10).

Approximately $80-90 \%$ of $n$ - hexane can be absorbed by inhalation and then distributed to lipid rich tissues and organs such as the brain, peripheral nerves, liver, spleen, kidney and adrenal glands (11).

The study was performed to investigate the role of $\mathrm{ZW}$ as antioxidant against histological changes that occurring in renal damage induced by $n$ - hexane intoxication in rats by using immunohistochemistry technique.

\section{Material and methods}

The study was carried out at Environmental Toxicology Laboratory, Department of Environmental Studies, Institute of Graduate Studies and Research, Alexandria University, Alexandria, Egypt. N-Hexane (purity 99\%0 from was purchased from Sigma Aldrich Chemical Co. (St. Louis, MO, USA). Zamzam water samples were obtained directly from well in Makka Saudia Arabia, the samples were treated with UV for sterilization and than prepared in sterilized bottle (5 Liter). Expermintal animals (20) male albino rats weighing $150-170 \mathrm{~g}$ were obtained from the animal house of the Faculty of Medicine, Alexandria University. Animals were handled in accordance with the principles of laboratory animal care as contained in 
NIH guide for laboratory animal welfare and the experimental protocol was approved by Local Ethics Committee and Animals Research. The rats were housed in stainless steel bottomed wire cages after grouping to four groups (5 rats in each cage ) and maintained at a temperature of $22 \pm 2{ }^{\circ} \mathrm{C}$, relative humidity of $40-60 \%$, with a $12 \mathrm{~h} / 12 \mathrm{~h}$ light/dark cycle and allowed free access to food and water beside Zamzam water according Saif et al (5). The test substances were administered to the animals according to the following experimental protocol: Group I (control): Control rats were fed basal diet and given tap water $(100 \mathrm{ml} /$ cage ) as drinking water daily for ten days.

Group II (n- hexan): Rats were fed basal diet and given tap water $(100 \mathrm{ml} /$ cage $)$ as drinking water daily for five days, after that given (n-hexan 300uL/kg .B.W) mixed with $(0.5 \mathrm{ml})$ corn oil to each rat for last five days of experimental, with continuous drinking with tap water .

Group III (Zamzam water): Rats were fed with basal diet and given $(100 \mathrm{ml} /$ cage $)$ as drinking water daily for ten days.

Group IV (n-hexan + Zamzan water ): Rats were fed with basal diet and given $(100 \mathrm{ml} /$ cage $)$ of Zamzam water as drinking water daily for five days, after that given n-hexan $300 \mathrm{uL} / \mathrm{kg}$.B.W) mixed with $(0.5$ $\mathrm{ml}$ ) corn oil to each rat for last five days of experimental with continuous given Zamzam water .

At the end of the experimental period, the rats were over night fasted (control and experimental animals), and sacrificed after 24 hours of last dose of different administration under light ether anesthesia. Kidney tissues of each rat were immediately removed taking care to handle specimens gently to minimize trauma, weighted and put into $10 \%$ neutral buffer formalin as a fixative solution. Fixation time was limited to 24 hours and the fixed tissues were stored in $70 \%$ ethyl alcohol until they were processed. The fixed tissues were dehydrated through a graded series of ethanol and embedded in paraffin, sectioned, deparaffinized and rehydrated and washed in phosphate buffered saline and PCNA immunoreactivity was performed according to Tousson et al. (12). Kidney distribution of $\mathrm{Ki}-67$ or P53 receptor subunits were examined in deparaffinized sections $(5 \mu \mathrm{m})$ using an Avidin-Biotin-Peroxidase $(\mathrm{ABC})$ immunohistochemical method (Elite-ABC, Vector Laboratories, CA, USA) with Ki-67 and P53 monoclonal antibody (dilution 1:100; DAKO Japan Co, Tokyo, Japan).

\section{Statistical Analysis:}

Statistical analyses were made with oneway analysis of variance (ANOVA) to compare the experimental groups (SPSS 
for windows version 17). $\mathrm{P}<0.05$ was

considered statistical significance.

\section{The Results}

Table (1) Relative kidney weights of rats exposed to n- hexane and pretreatment with

zamzam water

\begin{tabular}{|c|c|c|c|c|c|c|c|c|}
\hline $\begin{array}{c}\text { Exp } \\
\text { rats }\end{array}$ & \multicolumn{2}{|l|}{ Control group } & \multicolumn{2}{l|}{-hexane group } & \multicolumn{2}{|l|}{ ZW group } & \multicolumn{2}{l|}{ ZW + n-hexane group } \\
& $\mathrm{R}$ & $\mathrm{L}$ & $\mathrm{R}$ & $\mathrm{L}$ & $\mathrm{R}$ & $\mathrm{L}$ & $\mathrm{R}$ & $\mathrm{L}$ \\
1 & 0.62 & 0.65 & 0.72 & 0.71 & 0.55 & 0.58 & 0.64 & 0.66 \\
2 & 0.53 & 0.55 & 0.77 & 0.74 & 0.52 & 0.54 & 0.66 & 0.64 \\
3 & 0.53 & 0.52 & 0.66 & 0.69 & 0.57 & 0.55 & 0.58 & 0.61 \\
4 & 0.48 & 0.51 & 0.80 & 0.84 & 0.49 & 0.51 & 0.56 & 0.59 \\
5 & 0.56 & 0.54 & 0.73 & 0.78 & 0.51 & 0.53 & 0.63 & 0.68 \\
Total & 2.72 & 2.77 & 3.68 & 3.76 & 2.64 & 2.71 & 3.07 & 3.18 \\
Mean & $0.54 \pm$ & $0.55 \pm$ & $0.73 \pm$ & $0.75 \pm$ & $0.52 \pm$ & $0.54 \pm$ & $0.61 \pm$ & $0.63 \pm$ \\
$+\mathrm{SD}$ & 0.07 & 0.05 & 0.06 & 0.08 & 0.04 & 0.07 & 0.06 & 0.07 \\
\hline
\end{tabular}

Table (1) showed weight of the kidneys obtained from the rats in the experimental groups; the results observed significantly increase in the weight of the kidneys in the group treated with n-hexane in compared with control group, also relative decrease in weight of the kidneys in the group co-treatment with Zamzam water and n-hexane.

The present study showed detection and distribution of PCNA immunoreactivity (PCNA-ir) in the histo sections of the kidney in different groups of the study which found as following:

Sections of the group (I) which represent control group the rats given $(100 \mathrm{ml} / \mathrm{cage})$ tap water observed faint positive reaction in the glomrelous and renal tubules (Fig. 1). 


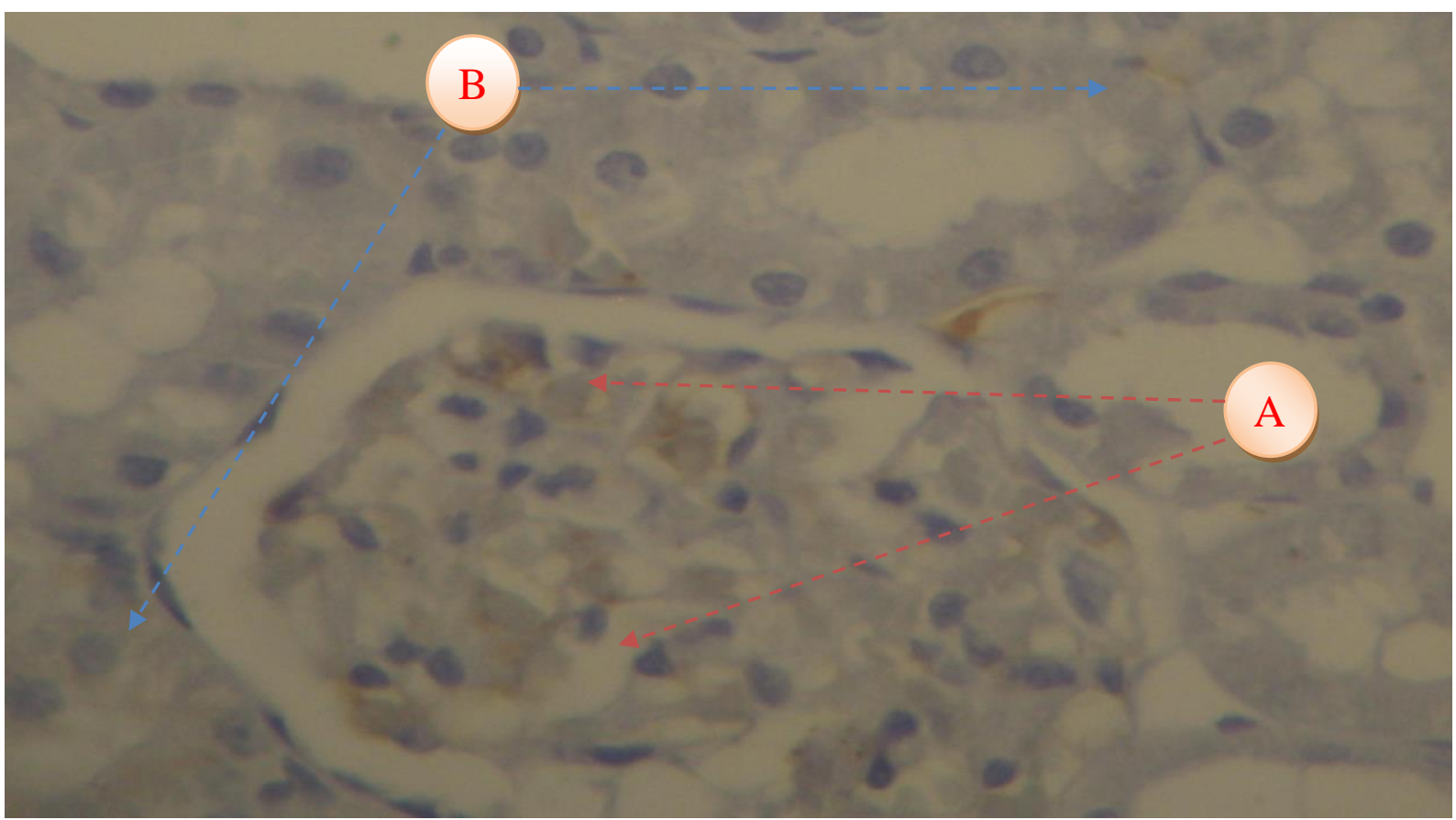

Figure (1): High power micrograph of rat kidney section in control group stained with (PCNA-ir) revealed faint positive reactions in the $(\mathrm{A})$ : glomrelous and $(\mathrm{B})$ : renal tubules.

Section of group ( II ) which represent $\mathrm{n}$ - hexan group the rats were given tap water $(100 \mathrm{ml} / \mathrm{cage})$ as drinking water daily, after that given n-hexan in dose $(300 \mathrm{uL} / \mathrm{kg}$.B.W) which observed strong positive reactions for PCNA-ir in the glomrelous and renal tubules (Fig 2), with sever changes in the malpighian capsules and the glomerulei appear in irregular shape ,renal tubules marked degeneration epithelium and srong cytoplasmic vaculation,(Fig 3).

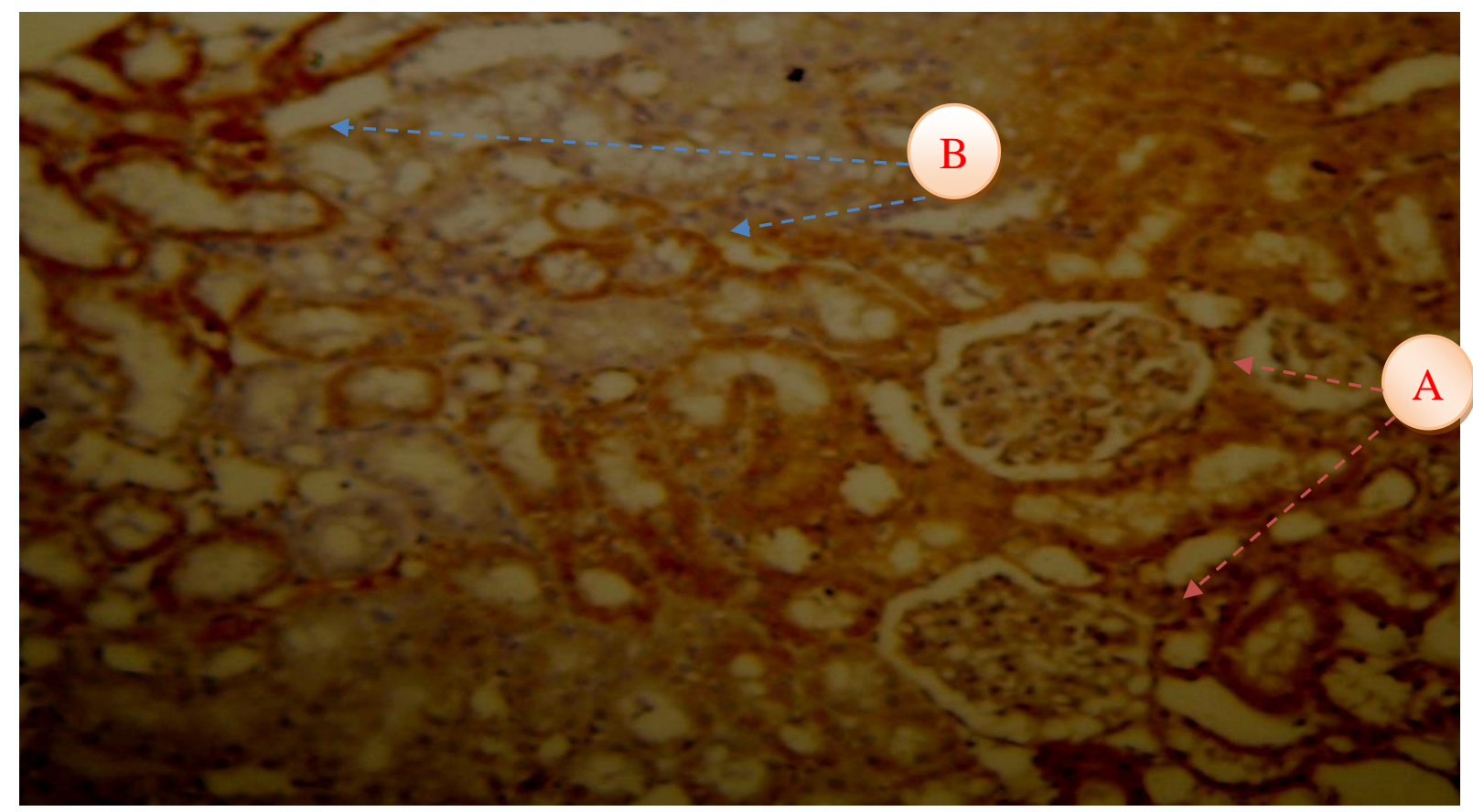


Figure (2): High power micrograph of rat kidney section in $n$ - hexane group stained with (PCNA-ir) revealed strong positive reactions for PCNA-ir in the (A): glomrelous and (B): renal tubules.

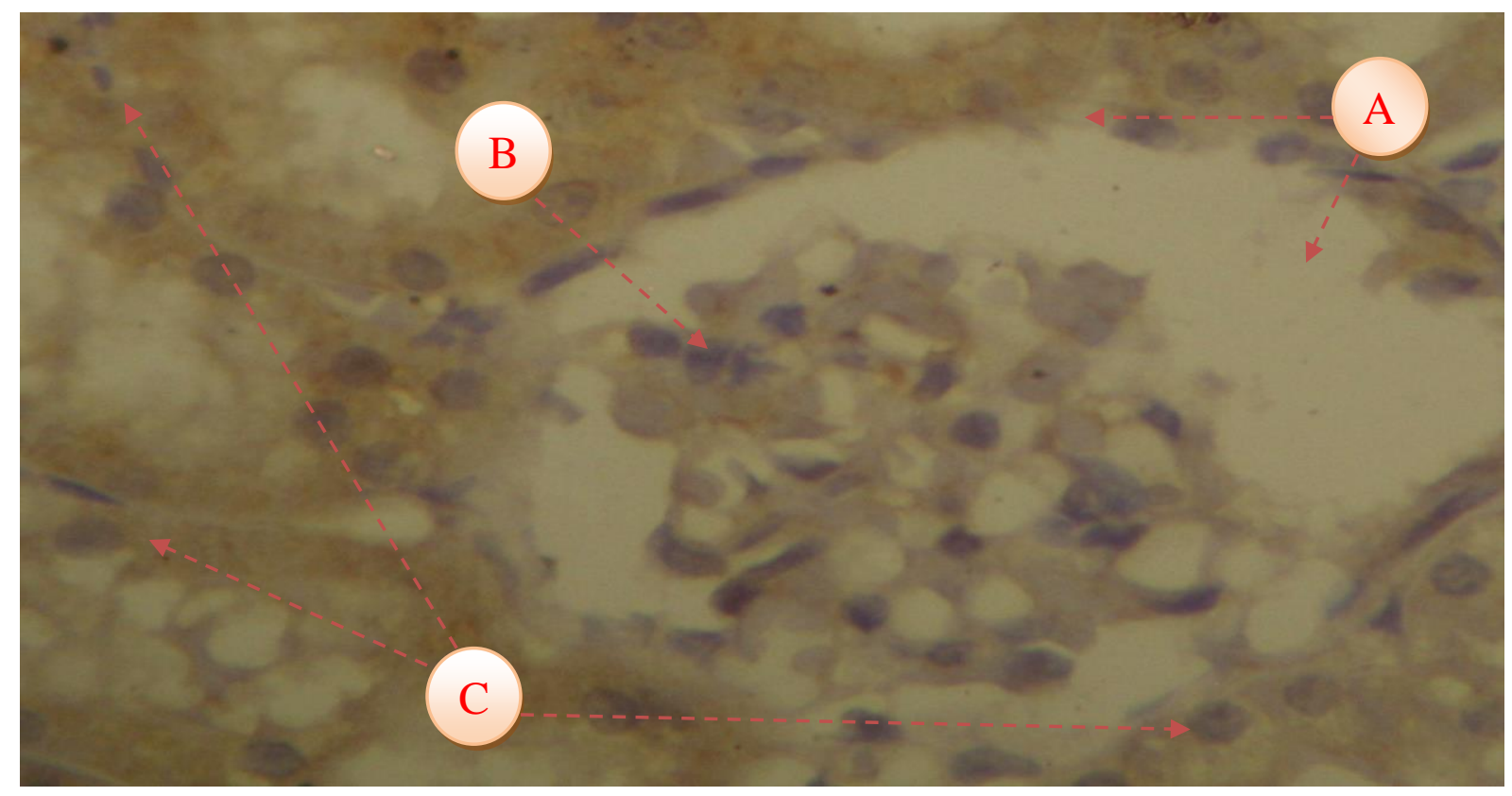

Figure (3): High power micrograph of kidney section stained with (PCNA-ir) revealed A: changes in the malpighian capsules, B: irregular shape in the glomerulei , C: degeneration epithelium of renal tubules.

Section of the group (III) which represent the rats that given (100ml/cage ) Zamzam water as drinking water daily for ten days which revealed normal structure of malpighian capsules and normal corpuscles with faint positive reaction in the glomrelous and renal tubules (Fig 4).

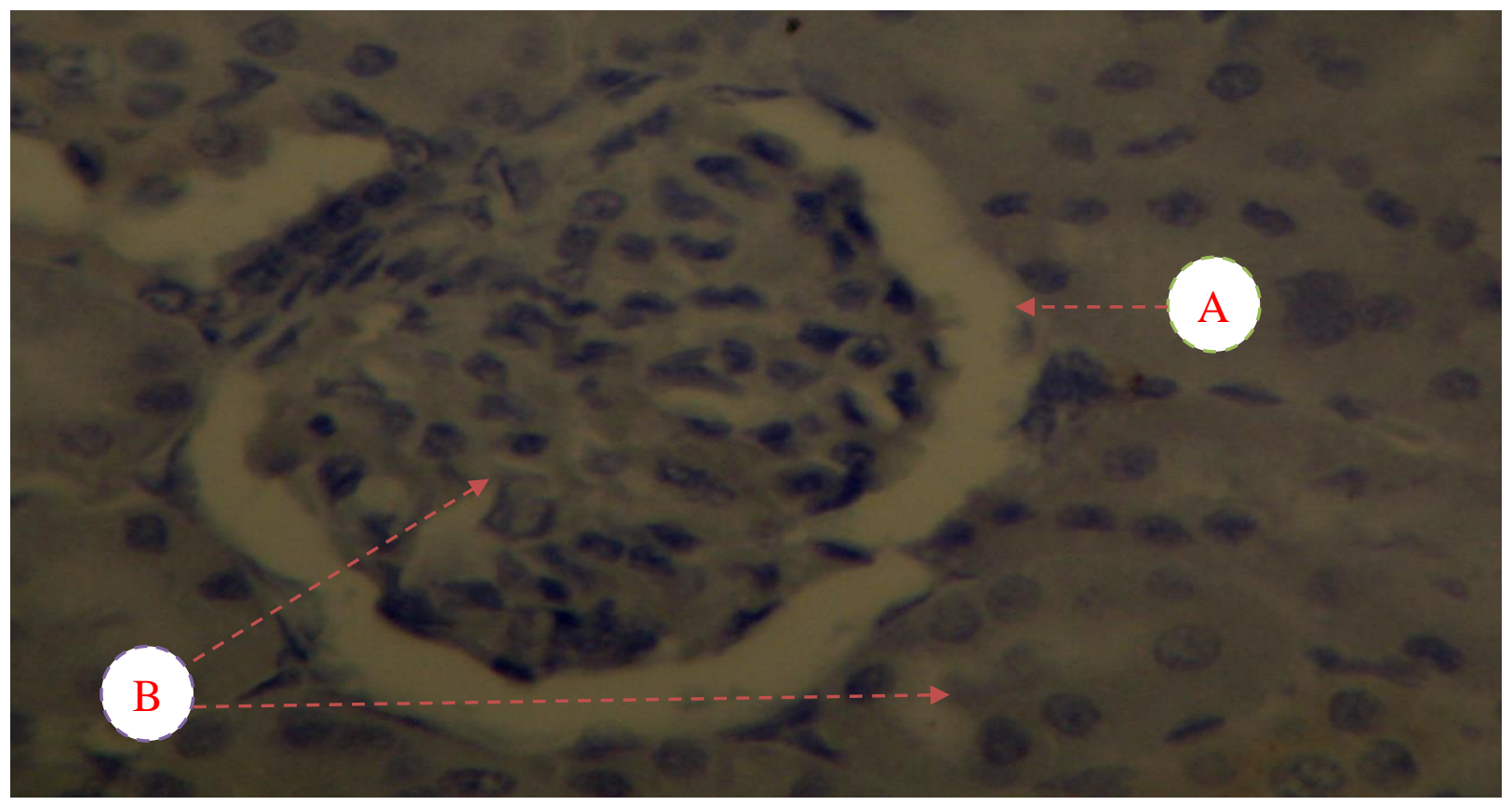

Figure (4): High power micrograph of rat kidney section with Zamzam water stained with (PCNA-ir) revealed (A): normal structure of malpighian capsules and (B): normal corpuscles and renal tubules. 
Section of group ( IV) which represent group of rats that given (100ml/cage ) of Zamzam water for five days and given n-hexan $(300 \mathrm{uL} / \mathrm{kg}$.B.W) for last five days with continuous given Zamzam water ,pre -treatment with Zamzam water revealed normal structure of malpighian capsule and renal tubules with moderate degeneration of epithelia cell ,(Fig $5)$.

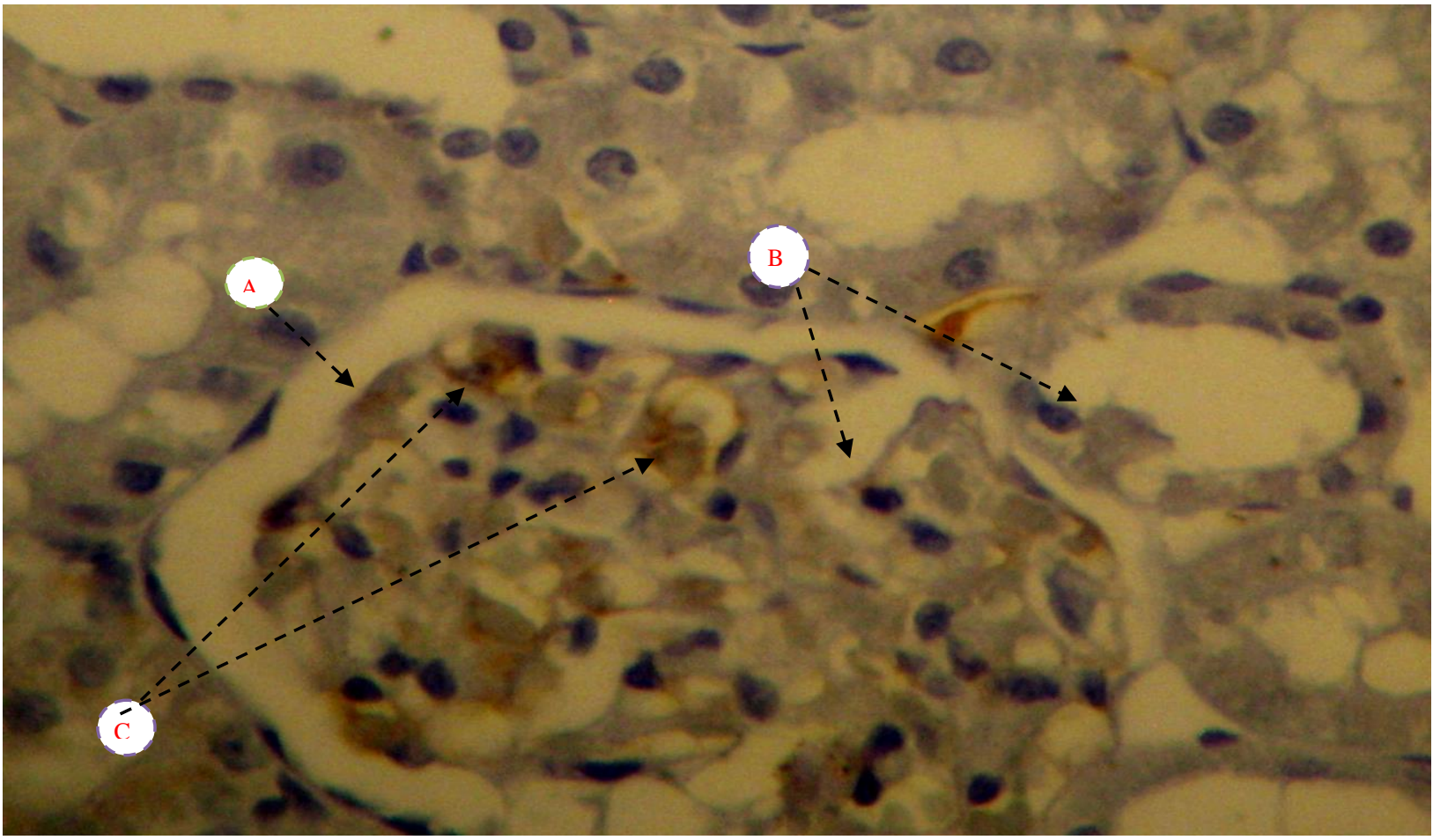

Figure (5): High power micrograph of rat kidney section with (n- hexane + Zamzam water) stained with (PCNA-ir) revealed (A): normal structure of malpighian capsule and corpuscle, (B): moderate changes in some capsules and renal tubules $\quad(\mathrm{C})$ : moderate positive with PCNA-ir and moderate degeneration of epithelial cells .

\section{$\underline{\text { Discussion }}$}

Oxidative stress, an imbalance between oxidant and antioxidant mechanisms in animal bodies, has been implicated in many diseases and their complications $(\mathbf{1 3}, 14,15)$. This imbalance may result either form excessive exposure to pro-oxidants or from compromised anti-oxidant mechanisms. The later may result from deficiency of essential elements or from incapacitation of disease, while the former might emanate from exposure to exo-genous toxins or the pathologic stress of disease $(\mathbf{1 6}, \mathbf{1 5})$. Thus, oxidative stress may occur in normal animals when antioxidant mechanisms are not working properly as in dietary deficiencies of vitamin $\mathrm{E}$, vitamin $\mathrm{C}$ or the essential elements like selenium, zinc, and manganese among others.

Exposure to exogenous toxins is still another mode for inducing oxidative stress as in the 
toxicity of some drugs like gentamicin or industrial chemicals like carbon tetrachloride (16). Ap-parently then, oxidative stress can be combated by strategies that promote and foster the antioxidant defense mechanisms. Water has been shown to strengthen the antioxidant capacity of animal bodies (17). Most of the work in this respect focused on alkaline water, which has been reported to reduce oxidative stress in patients with chronic renal disease (18)

In the present study, exposure to n-hexane caused a significant increased the relative kidney weights of treated rats, thus indicating an overt general organ toxicity in the rats due to inflammation and swelling of kidneys exposed to n-hexane, while pretreatment with zamzam water led to decrease in the weight and inflammation in kidneys in group four (19). Zamzam wells located in Makkah, which is the hard of the hajj pilgrimage, standing only few masters east of Al-Kabbah (1). Abdullah et al. (20) reported that the alkaline ionized water consider a major safe strategy in management of metabolic acidosis secondary to renal failure or dialysis or urinary diversion.

The results of this study were observed faint positive reaction in the glomrelous and renal tubules in control and the group that given Zamzam water to PCNA-ir, but showed strong positive reaction for PCNA-ir in kidney sections of rats treated with n- hexane intoxication and moderate positive reaction in rats group was co- treatment of n- hexane and zamzam water. This results were agreed with the study performed by Ajamia (21) who's used Dimethyl disulphate as intoxication with damiana as antioxidant, which showed the detection and distribution of PCNA-ir immunoreactivity (PCNA-ir) in the kidney sections, where found faint positive reaction in control and Damiana group and strong positive reaction for PCNA-ir in kidney sections for rats treated with Dimethyle disulphide and moderate positive reactions for PCNA -ir were observed in urinary tubules after co - treatment of DMD with damiana .

Kidney susceptibility to toxic insult by environmental pollutants is partly a consequence of the high blood volume supplied to the kidneys and the role it plays in concentrating solutes. The kidney is the critical target organ for xenobiotic compounds which produce a variety of renal toxic effects involving tubular cells and glomerulus. Some compound such as n- hexane can cause inhibit incorporation of amino acid in to protein causing increase in urea levels $(\mathbf{2 2 , 1 9 )}$.

Isaac et al (23) were reported the renal dysfunction clearly evidenced in n-Hexane treated groups as revealed by the elevation in serum urea, creatinine and uric acid (uric acid consider arisk factor in development myocardial infraction) and increase in creatinine and urea levels indicate diminished 
ability of the kidneys to filter these waste products from the blood and excrete them in the urine.

Increased serum urea, creatinine and uric acid levels reflect the diagnosis of renal failure. Moreover, elevated blood urea is known to be correlated with an increased protein catabolism in mammals and/or the conversion of ammonia to urea as a result of increased synthesis of arginase enzyme involved in urea production. The elevation in serum urea, creatinine and uric acid levels considered a significant marker of renal

dysfunction

(24).

Ajamia (21) was said that; rats treated with DMDS for three weeks showed significant decrease in protein content in rat kidney, while increased after Damiana administration. The decrease in the levels of protein in DMDS treated rats might be due to changes in protein synthesis and/or its metabolism and all measured parameters showed a significant change near the normal level with damiana cotreatment as compared with DMDS treated groups.

In study was performed by Saif et al (5) to investigate if zamzam water similar alkaline water against hepatotoxicity induce by (CCL4) in rats ,the results observed a significant reduction indicating the effect of $\mathrm{ZM}$ in restoring the normal structural and functional ability of the hepatocytes, suggests use of ZW as a hepato protector agent in the diet of patients with hepatopathes . In histopathological studies that performed by Isaac et al (23) on the kidney tissue sections obtained from rats exposed to n-Hexane for (21) days revealed a histopathological alterations in glomeruli and some parts of the urinary tubules, with severe changes in the Malpighian and corpuscles which lost their characteristic configuration, the glomerulei lose their regular round to oval shape and the renal tubules appeared with marked degenerated epithelium, strong cytoplasmic vacuolation and wide lumen. Most of the work in this respect focused on alkaline water, which has been reported to reduce oxidative stress in the patients with chronic renal disease (Huang et al., 2003). Zamzam water is ionized water (negative water) because it has negative charge and show strengthen to antioxidant capacity of animal bodies and reduce oxidative stress in the patients with chronic renal disease (5).

In conclusion, it is clear that n-Hexane induced pronounced hazardous effects on kidney and exposure to n- hexane showed higher toxic effect with sever inflammation treatment with damiana alone improved the antioxidant status of rats and could be useful as antioxidant against environmental stress induced by petrochemicals toxic chemicals

\section{References}


1- Khalid, N., Ahmad, A., Khalid, S., Ahmed, A., Irfan, M. Mineral composition and health functionality of zamzam water: A Review. International Journal of Food Properties, 17(3), 661-677.

2- Naeem, N., Alsanussi, H., Almohandis, A.Multielemental and hydrochemical study of holy Zamzam water. Journal of the New England Water Works Association, 97(2), 159-169 (2011).

3- Alfadul, S.M., Khan, M.A. Water quality of bottled water in the kingdom of Saudi Arabia: A comparative study with Riyadh municipal and Zamzam water. Journal of Environmental Science and Health, Part A, 46(13), 1519-1528 (2011).

\section{4- Al ZuhairN, Khounganian R.}

Comparative study between the chemical composition of potable water and Zamzam water and its effect on tooth structure in Saudi Arabia, Afaq (Arabic) Dental Journal;11: 3637 (2006).

5- Saif A., Sarhan OM., Elmogy M., Mutwally H. Hepatoprotective Effects of Zamzam water against Carbon Tetrachloride Induced Liver Damage in Rats: Biochemical, Histopathological, and molecular Evidences. Life Science J, 11(10):1-9 (2014).

6- Tsai, C.F., Hsu, Y.W., Chen, W.K., Ho, Y,C., Lu, F.J. Enhanced induction of mitochondrial damage and apoptosis in human leukemia HL-60 cells due to electrolyzed-reduced water and glutathione.
Bioscience, $J$ of Biotechnology, and Biochemistry, 73(2), 280-287(2009).

7- Ali, A.F.M., Cosemi, E., Kamel, S., Mohammed, S., Elhefnawy, M., Farid, L., Shaker, S.Oncolytic action of Zamzam water on azoxyonethone (AOM) induced colon tumors in rats. In Thirteenth International Water Technology Conference, IWTC, 13, 1521-1526, (2009).

\section{8- Khan AA and Alzohairy $M$.} Hepatoprotective effects of camel milk against CCl4- induced hepatotoxicity in Rats. Asian J Biochem., 6(2):171-180(2011).

9- Palmer, Brian. "A study found hexane in soy protein. Should you stop eating veggie burgers?". Slate.com. Retrieved 2015-0317(2010).

10Gilbert,S.N-hexane:Overview. Toxipedia (TXP-2).Coonnection Science and People.

11- Liu, C. H.; Huang, C. Y.; Huang, C. C. (2012). "Occupational Neurotoxic Diseases in Taiwan". Safety and Health at Work. 3 (4): 257-67 (2014).

12- Tousson E, Ali EM, Ibrahim W, Mansour M.A. Proliferating Cell Nuclear Antigen as a Molecular Biomarker for Spermatogenesis in PTU-Induced Hypothyroidism of Rats. Reprod Sci. 18 (7): 679-686(2011).

13- Wei W, Liu Q, Tan Y, Liu L, Li X, Cai L. Oxidative stress, diabetes, and diabetic 
complications. Hemoglobin 33:370377(2009).

\section{4- Reuter S, Gupta SC, Chaturvedi MM,} Aggarwal BB. Oxidative stress, inflammation, and cancer: how are they linked? Free Radic. Biol. Med. 49:16031616(2010).

15- Pitocco D, Zaccardi F, Di Stasio E, Romitelli F, Santini SA, Zuppi C, Ghirlanda G. Oxidative stress, nitric oxide, and diabetes. Rev Diabet Stud. 7:1525(2010).

16- Narayana K. An aminoglycoside antibiotic gentamycin induces oxidative stress, reduces antioxidant reserve and impairs spermatogenesis in rats. J. Toxicol. Sci. 33:85-96(2008).

\section{7- Nassini R, Andrè E, Gazzieri D, De} Siena G, Zanasi A, Geppetti P, Materazzi S. A bicarbonate-alkaline mineral water protects from ethanol-induced hemorrhagic gastric lesions in mice. Biol. Pharm. Bull. 33:1319-1323(2010).

\section{8- Huang KC, Yang CC, Lee KT, Chien}

CT. Reduced hemodialysis-induced oxidative stress in end-stage renal disease patients by electrolyzed reduced water. Kidney Int. 64:704-714(2003).

19- Amresh, P. N. Singh, and C. V. Rao, "Toxicological screening of traditional medicine Laghupatha (Cissampelos pareira) in experimental animals," Journal of Ethnopharmacology, vol. 116, no. 3, pp. 454460, (2008).

20-

Abdullah,AM.;Abdelsalam,E.;Abdullah,B.; Khaled,A.(2012).Antioxident effect of Zamzam water in normal rats and those under induced -oxidative stress.JMED.PlantResch,Vol.6(42),pp:55075512 .

21- Agamia ,SM.A study on protective effect of medicinal herb against chemicals induced oxidative stress in petrochemicals industry .Thesis $\mathrm{PhD}$ :Environmental studies Dept. GSR. Alxandria Uni. Egypt. PP: 55-114 (2016).

22- Hussain, T. \& Ahmed, M. Zam Zam water: Scientific research findings. Al-Islaah publications. Imam Muslim on authority of AbiTharr. 2473 (2010).

23- Isaac A., Amos OA., Isioma JO.,Omoloja AO. Impairment of Hepatic and Renal Functions by 2,5-Hexanedione Is Accompanied by Oxidative Stress in Rats. $J$. Toxicology, Vol: , Article ID 239240, P: 9 (2014).

24- El-Demerdash, F.M. Cytotoxic effect of fenitrothion and lambda-cyhalothrin mixture on lipid peroxidation and antioxidant defense system in rat kidney. J. Environ. Sci. Health B47: 262- 268(2012). 